\title{
Educação em biossegurança e bioética: articulação necessária em biotecnologia
}

\author{
Education on biosafety and bioethics: \\ necessary articulation in biotechnology
}

M arcos De Bonis ${ }^{1}$

$M$ arco Antonio Ferreira da Costa ${ }^{2}$

\footnotetext{
${ }^{1}$ Departamento de Virologia, Instituto de Microbiologia Prof. Paulo deGóes, UFRJ.Av. Trompowsk s/n, Cidade Universitária. 21941-590 Rio dejaneiro RJ. debonism@micro.ufrj.br ${ }^{2}$ Escola Politécnica de SaúdeJ oaquim Venâncio, Fiocruz.
}

\begin{abstract}
Science education has been discussed in some segments of the society and, international organizations have encouraged nations to invest in this strategic area. In this context, education in bioethics and bi osafety explores a rich content on prevention, standards and ethical principleswhich serve to guide the paths track by biotechnology. The recovery of bioethics and biosafety, as part of an educational policy scientific, effective and consistent, can stimulate the formation of individuals with a scientific and citizen awareness, in a position to participate on ethical and technological issues produced by biotechnology.
\end{abstract}

Key words Science education, Biosafety, Bioe thics, Biotechnology
Resumo A educação científica tem sido debatida em alguns segmentos da sociedade e organizações internacionais têm estimulado as nações a investi rem nessa área tão estratégica. N esse contexto, a educação em bi ossegurança e bioética explora um conteúdo rico em prevenção, normas e princípios éticos, que servem para nortear os caminhos triIhados pela biotecnologia. A valorização da biossegurança e da bioética como partede uma política educacional científica, efetiva e consistente, pode estimular a formação deindivíduos com uma consciência científica e cidadã, em condições de participar das questões de natureza ética e tecnológica produzidas pela biotecnologia.

Palavras-chave Educação científica, Biossegurança, Bioética, Biotecnologia 
Introdução

Diante dos avanços científicos e tecnológicos e do fenômeno da globalização que ocorrem numa velocidade jamais vista, a educação no planeta tem sido revista por diversos setores da sociedade. Um exemplo disso é referido por Torres ${ }^{1}$ no que tange à atuação do Banco Mundial, o qual apresenta propostas para a educação básica dos indivíduos, ocupando um espaço que normalmente seria ocupado pela Unesco, entre outras organizações importantes. $\mathrm{M}$ achado ${ }^{2}$ chama atenção para o fato de que as novas tecnologias exigem mão-de-obra especializada e que as mudanças nas relações sociais queacontecem deforma acelerada como consequência das novas tecnologias fazem emergir na sociedade a necessidade de uma educação contextualizada com o momento histórico vivido.

Os desafios propostos para a educação no século XXI aparecem no relatório denominado "Relatório Jacques Delors", elaborado pela Comissão Internacional sobre a Educação para o século XXI, da Organização das Nações Unidas para a Educação, Ciência e Cultura (Unesco).

Esterelatório foi publicado no Brasil, em 2000, sob o título de "Educação - um tesouro a descobrir" ${ }^{3}$, com a proposta central de que a educação do indivíduo deve passar pelas fases do aprender a conhecer, aprender a fazer, aprender a viver e aprender a ser. Nessa linha de raciocínio, há um consenso entre os educadores de que a agregação destes fatores corrobora, significativamente, para o estabelecimento de novas relações entreo homem ea vida. Visando ampliar a maneira de compreender e de perceber determinadas situações na educação e, consequentemente, explorar deforma interdisciplinar e transdisciplinar os saberes, a Unesco publicou o livro "Os sete saberes necessários à educação do futuro", escrito pelo pensador francês Edgar M orin ${ }^{4}$. Este autor destaca a necessidade da educação ser um processo de formação integral, que entendemos como 0 desenvolvimento da inteligência racional, da inteligência emocional e da inteligência volitiva do indivíduo e não somente distinção de al guns aspectos do seu ser.

O tema da educação e sua importância para o desenvolvimento sustentável foi objeto da 57ạ reunião da Assembléia-Geral das Nações Unidas, na qual se proclamou o período 2005-2014 como a década da educação para o desenvolvimento sustentável ${ }^{5}$ e, simultaneamente, designava a Unesco como agência responsável pela promoção e aplicação da década. N esta declaração, está suben- tendida e explícita a necessidade de se ter uma educação de qualidade, bem como aprender valores para no futuro poder respeitar as diferenças, as diversidades e os "outros". N esse sentido, a educação facilita o entendimento sobre nós mesmos e sobre os "outros", além de propiciar a compreensão do ambiente natural e social do mundo. A base de sustentação dessas idéias é 0 respeito ao "outro". A construção de alteridade em biotecnologia passa pela responsabilidade mútua entre a sociedade, cientistas e governo.

Quanto à alfabetização científica, Praia et al. ${ }^{6}$ têm debatido o ensino da natureza da ciência e da educação científica, com o objetivo de preparar cidadãos com uma formação científica que os habilitea participar de discussões tecnocientíficas etambém de poder participar de tomada de decisões científicas visando ao interesse social.

A necessidade da sociedade de estar presente nas discussões e na tomada de decisões se faz necessário, segundo Fukuyama ${ }^{7}$, porque, na sua visão, a ameaça da biotecnologia é muito sutil e de difícil consenso em qualquer situação que ela esteja envolvida.

Nesses contextos, a educação em biossegurança ebioética torna-se respectivamente instrumento normativo preparatório e formador do caráter científico dos indivíduos que vão produzir produtos biotecnológicos.

Este artigo, portanto, tem como objetivo discutir, à luz da perspectiva cognitivista-construtivista ${ }^{8}$ a inserção da biossegurança e da bioética na formação do indivíduo para o exercício de práticas biotecnológicas com responsabilidade, tendo como premissa que o desafio da biotecnologianão é meramente de caráter ético, mas também político.

\section{Educação em biossegurança e bioética}

O desenvolvimento da biotecnologia suscita uma série de preocupações tanto para cientistas quanto para a sociedade de maneira geral. Dentre essas preocupações, destaca-se a necessidade de se alfabetizar cientificamente a sociedade para que esta saiba se posicionar frente às demandas científicastecnológicas atuais. Este assunto é controverso e muitos autores têm se dedicado a debatê-109-16.

A Conferência M undial sobre a Ciência para o Século XXI: um novo compromisso, ocorrida em Budapeste, no período de 26 de junho a 2 de julho 1999, patrocinada pela Organização Educacional, Cientifica eCultural das Nações U nidas (Unesco) e pelo Conselho Internacional para a 
Ciência (ICSU), produziu a Declaração sobreCiência e o U so do Conhecimento Científico ${ }^{17}$, na qual sugere que [...] a criação e manutenção de institui ções nacionais para determinação dos riscos e gerenciamento, redução de vulnerabilidade, segurança e saúde; e [...] consequências de novos descobrimentos e tecnologias recentemente desenvolvidas devem ser protegidas para que os problemas éticos possam ser discutidos de uma maneira apropriada. Percebe-se, nesse documento, implicitamente a preocupação com a biossegurança e a bioética.

A abordagem da educação científica, neste estudo, voltada para a biossegurança e bioética, não traduz uma posição reducionista e sim um enfoque direcionado para a biotecnologia, a qual carrega grandes enovas interrogações éticas, exigindo, assim, uma articulação interdisciplinar a fim de poder atender a um espectro amplo de preocupações de caráter humanitário, ético, científico ecultural.

A biossegurança não se resume somente a normas de prevenção e controle; a sua dimen são científica requer dos indivíduos uma formação educacional adequada para a compreensão eexecução dos seus objetivos. N esse sentido, Costa e Costa ${ }^{9}$ se expressam [...] os processos educacionais de biossegurança devem ser pedagogicamente estruturados para que sejam capazes de gerar competências atualmente demandadas para os profissionais da saúde em todos os níveis.

0 avanço da biossegurança em áreas que também requerem formação adequada dos indivíduos nelas inseridos é comentado por Costa ${ }^{18}$ : A realidade do mundo biotecnológico se apresenta como um processo aparentemente sem limites, e a biossegurança que em termos clássicos pode ser definida como a segurança ocupacional e ambiental da moderna biotecnologia, de forma contraditória, começa a ocupar espaços em ambientes não-biotecnológicos, como hospitais, laboratórios de saúde pública, hemocentros, etc.

A formação adequada a qual nos referimos é uma educação voltada para a preparação de indivíduos que seriam submetidos a uma alfabetização científica ${ }^{19}$, visando ao desenvolvimento de sua cognição.

Sabe-se quea expressão alfabetização científica possui várias definições ${ }^{20-31}$. Segundo os autores Schulze et al. ${ }^{32},[\ldots]$ o termo alfabetização científica foi empregado pela primeira vez apenas nos anos 1950 por Paul Hurd ${ }^{29}$, desde então, a literatura sobre o conceito tornou-se extensa e diversificada (Durant ${ }^{33}$, Laugksch ${ }^{34}$, M iller $^{21,35}$, Waterman ${ }^{36}$ ), admitindo diferentes concepções de alfabetização científica, adotadas em função de propósitos distintos para os quais o conceito é utilizado, Jenkins ${ }^{37}$.

Dentreas muitas concepções dealfabetização científica, achamos relevante à postulada por M iller ${ }^{21}$, em que enuncia uma definição de alfabetização científica composta de três importantes pilares: o primeiro é sobre a aprendizagem de conceitos e nomenclaturas que são indispensáveis em ciência; o segundo, entendimento de modelos, padrões ou normas, bem como saber discriminar o que se deve utilizar em termos de processos, técnicas e métodos; o terceiro, perceber, divisar e formar idéia a respeito do efeito quase sempre devastador que tanto a ciência quanto a tecnologia provocam sobre os indivíduos em uma sociedade, quando se trata de alterar conceitos já estabelecidos. Essa proposta de encarar a alfabetização científica baseada nesses pilares foi aceita pela American Association for the Advancement of Science (AAAS) ${ }^{20}$ que, em 1989, formulou sua própria política de alfabetização científica baseada nesse tripé.

Na nossa percepção, os pilares propostos por Miller permitem desenvolver, de maneira muito objetiva, ações em biossegurança e bioética, visando atuar nos processos e nos resultados biotecnológicos. Além disso, contribuem para o surgimento de uma concepção cidadã plena nos indivíduos ${ }^{38-40}$. Estas etapas, sendo executadas de forma competente, poderão no futuro torná-lo um profissional com consciênciacidadã, queexercerá atividadecientífica ou não. Essa mentalidade éconstruída a partir de uma posição construtivista ${ }^{8}$, criando um comprometimento do indivíduo com o conhecimento e o trabal ho.

O impacto causado pela biotecnologia na sociedade, juntamente com o surgimento de novas tecnologias, abriu um leque de discussão em que acaba sobressaindo a necessidade de se discutir biossegurança e bioética de forma articulada. Temas como clonagem de embriões humanos, animais transgênicos, organismos geneticamente modificados (OGM) no ambiente, terapia gênica, células-tronco, entre outros, são assuntos pelos quais a opinião pública sempre manifesta preocupação.

O neurocientista Stevens Rehen, da Universidade Federal do Rio de Janeiro (UFRJ), deu uma declaração que foi reproduzida no informativo Jornal da Ciência ${ }^{41}$, produzido pela Sociedade Brasileira para o Progresso da Ciência, apresentando suas impressões a respeito do fato do Supremo Tribunal Federal (STF) ter liberado as pesquisas com células-tronco embrionárias e da dificuldade de vários setores da sociedade de ab- 
sorver cientificamenteo assunto em foco eainda confundi-lo com outros temas que não têm relação com a questão. Em seu comentário, ele destaca que, para dar uma boa direção ao problema apresentado, é necessário investir na educação e cultura científica da população, acrescentando: "é mais uma questão de formação básica mesmo, que precisa melhorar".

Do lado governamental, a Coordenação de Biotecnologia em Saúde do M inistério daSaúde ${ }^{42}$ se posiciona da seguinte forma: N essa gama de novas e promissoras tecnologias, é imprescindível zelar para que seu desenvolvimento e incorporação à atenção à saúde obrigatoriamente respeitem parâmetros de segurança e princípios morais de nossa sociedade, o que qualifica uma estrei ta interface da biotecnologia com a biossegurança e a bioética.

0 pensamento de que a biotecnologia não precisa estar atrelada a valores morais e éticos é equivocado. Segundo M oser ${ }^{43}$, a biotecnologia não costuma retroceder em seus avanços; com ou sem diálogo, ela segue em frente; portanto, a reflexão ética deveser obrigatória. A educação em biossegurança e bioética não tem a pretensão de resolver todos os problemas colocados pelo de senvolvimento da biotecnologia; entretanto, são disciplinas fundamentaisque corroboram no sentido de se ter uma educação científica relevante em biotecnologia. Essa relevância pode ser evidenciada se for colocado em prática o que o filósofo Edgar M orin ${ }^{4}$ chama de "conhecimento pertinente". É preciso conjugar biossegurança e bioé tica, embora reconhecendo que cada parte tem sua finalidade e importância. A complexidade de cada disciplina leva a uma reflexão mais profunda quando o objetivo élevar o indivíduo a adquirir informações e saber aplicá-las em conjunto.

Em um mundo globalizado em que a necessidade de congruência se faz presente, biossegurança e bioética não se anulam e sim trocam informações, visando encaminhar racionalmente procedimentos e ações em biotecnologia. M orin ${ }^{4}$ acentua que essa idéia de congruência na educação passa pela complexidade das relações humanas, o que permite a inserção de conhecimentos espalhados em outras áreas do conhecimento, como as ciências humanas eda natureza. $\mathrm{N}$ a percepção de M orin ${ }^{4}$, é uma educação verdadeiramente paradigmática, porquemexe com todo um sistema estabelecido de produzir conhecimento.

\section{Educação, ética e política em biotecnologia}

Embora seja um documento de diretrizes para a prática da ciência, A D eclaração sobre Ciência eo Uso do Conhecimento Científico produzida na Conferência M undial sobre a Ciência para o Sé culo XXI: um novo compromisso ${ }^{17}$ recomenda algumas ações relacionadas à educação científica, à ética e à política, que também podem ser aplicadas à biotecnologia.

Este documento afirma que: “Educação de ciência, num sentido abrangente, sem discriminação e envolvendo todos os níveis e modalidades, éum pré- requisito para a democracia e para assegurar um desenvolvimento sustentável". Em outro tópico do documento, édestacado que [...] $M$ ais do que nunca é necessário desenvolver e expandir a alfabetização científica em todas as culturas e setores da sociedade bem como a habilidade de raciocinar e perícia e uma apreciação por valores éticos para que haja melhoramento na participação do público no processo de se fazer decisões relacionadas à aplicação do novo conhecimento.

Em matéria publicada no Jornal da Ciência ${ }^{44}$, o engenheiro Paulo Blikstein, formado pela Escola Politécnica da Universidade de São Paulo (USP), deu uma entrevista a respeito do seu trabal ho, o qual associa educação e tecnologia com o objetivo deter um ensino demelhor qualidade, tendo como base teórica às idéias do educador Paulo Freire.

Em sua dissertação de mestrado no M assachusetts Institute of Technology (MIT), trabaIhou com um grupo que se dedicava à questão da aprendizagem e posteriormente testou suas idéias em escolas públicas brasileiras eem al guns países com características educacionais semel hantes ao nosso. Em sua entrevista, ele destaca: "Se a gente realmente quer criar uma geração de cientistas para contribuir para o avanço tecnológico do Brasil, a gente tem de ensinar a ciência do século 21[...]".

A formação científica éum processo que não deve ser iniciado somente no ensino superior e sim no ensino médio, em que a capacidade cognitiva do aluno pode ser melhor explorada. Quando esse aluno chega ao ensino superior, se já tem uma base ou, em outras palavras, foi alfabetizado cientificamente, isso faz uma enorme diferença. Porém, para que essa diferença aconteça de fato, énecessário que o sistema educacional seja reestruturado, porque só mudar a grade curricular não será suficiente para produzir uma nova concepção de educação em ciência. 
Pode-severificar, no Plano de Desenvolvimento da Educação do M inistério da Educação (PDE) ${ }^{45}$, queno tópico referenteà Educação Profissional e Educação Científica, Decreto № 6.095, de 24 de abril de $2007^{46}$, os Institutos Federais de Educação, Ciência eTecnologia (IFET) se destacam com a proposta de [...] constituir-se em centro de excelência na oferta do ensino de ciências, voltado à investigação empírica; qualificar-se como centro de referência no apoio à oferta do ensino de ciências nas escolas públicas[...]. Essa medida visa, a médio elongo prazo, o incremento deações quevenham fortalecer o ensino de ciência, favorecer a qualificação e a capacitação de indivíduos para ciência e tecnologia e se enquadra nas recomendações estabelecidas na declaração.

Dentro dessa idéia de fortal ecimento da educação científica, $\mathrm{M}$ orin ${ }^{4}$ acrescenta mais um fator ao processo de formação científica do indivíduo, o preparo para enfrentar as incertezas na ciência, destacando que essas incertezas devem ser apresentadas aos indivíduos no seu processo de formação, a fim de que possam saber percorrer interativamente um espaço cercado de paradigmas estabelecidos. 0 autor faz a seguinteafirmação a respeito do conhecimento: "O conhecimento é, pois, uma aventura incerta que comporta em si mesma, permanentemente, o risco deilusão e de erro". O s conhecimentos de biossegurança articulados com os conhecimentos da bioética compõem uma estratégia para a diminuição dos riscos e das incertezas que podem derivar da complexidade que é biotecnologia. A estratégia aqui referida é um conjunto de diversos fatores que vão examinar as certezas e as incertezas do conjunto de circunstâncias apresentadas, bem como as probabilidades e improbabilidades do evento em biotecnologia.

Uma geração de indivíduos que sofra integralmente essas influências aprimorar-se-á cientificamentee, por conseguinte, a visão quea sociedade passa a ter, embasada e firmada em conhecimentos adquiridos durante o processo educacional de amadurecimento científico, deixa de ser uma visão apocalíptica e passa a ser um momento de debate construtivo, visando sempreao aperfeiçoamento do sistema biotecnológico vigente, nele incluído a bi ossegurança e a bioética.

\section{Em relação à ética}

Falar de ética em ciência significa fixar parâmetros para sua plena realização. N esse sentido, a Declaração sobre Ciência e o U so do Conheci- mento Científico ${ }^{17}$ destaca alguns pontos dos quais fazemos referência a dois: o primeiro, "OS cientistas eoutros personagen s principaistenham uma responsabilidade especial em evitar que a ciência venha ser usada de maneira não ética que possam consequentemente trazer resultados indesejáveis".

A biotecnologia, devido a sua natureza intervencionista, um exemplo da qual éa manipulação do patrimônio genético do ser humano, é geradora deprodutos manipulados geneticamente que causam grande impacto na sociedade e, consequentemente, produz preocupações de ordem ética.

Essas preocupações se evidenciam porquealgunsgrupos decientistas aceitam edefendem suas posições referentes às práticas biotecnológicas, baseando-se em uma concepção positivista que agregou a razão à ciência e encaminhou para um segundo plano a ética, associando-a à pouca elaboração intelectual $47-49$.

Como resultado, ocorreu um rompimento entreciência eética. Essa desconexão deve ser repelida e refutada segundo vários setores da sociedade, porque esta entende que a vida humana é um bem precioso para ficar sujeito a manipulações genéticas sem o controle, também, da sociedade ${ }^{7,43}$.

O segundo ponto é: Todos os cientistas deveriam se comprometer a altos padrões de ética, [...] A responsabilidade social dos cientistas exige que eles mantenham um alto padrão de integridade cientifica e controle de qualidade, partilha de seu conhecimento, comunica com o público e educa as gerações jovens. Os currículos científicos deveriam incluir ética das ciências [...]. 0 compromisso que cada pesquisador deve ter com a ética não deve ser apenas conceitual esim um compromisso que influencieconstantemente seus pensamentos eque esteja sempre presente em suas ações.

O exemplo para futuras gerações não deve ser visto como um idealismo ingênuo, porque se assim for compreendida a ética, os currículos científicos nunca abordarão as questões da ética e da bioética com a profundidade que deveser exigida para se examinar os problemas contemporâneos gerados pela tecnociência, em especial a biotecnologia.

$M$ orin ${ }^{4}$, ao referir-se à ética humana, chamaa de "antropo-ética", isto é, o indivíduo, a sociedade e a espécie formam um conjunto essencial da complexidade humana e, desta relação, manifesta-se a consciência eo espírito humano. Todos esses fatores são considerados fundamentais para ensinar ética para as próximas gerações. Para Morin ${ }^{4}$, dentre os objetivos da "antropo-ética" 
como a valorização da vida, o respeito ao "outro", a solidariedadee a compreensão, a ética deve orientar o indivíduo para exercer a cidadania ea democracia. No escopo dessas ideias, inclui-se a antinomia entre a biotecnologia e a bioética.

As decisões que são tomadas em biotecnologia geram uma difusão de responsabilidades que devem ser assumidas por quem as tomou, não podendo de forma alguma simplesmente ser ignoradas.

O princípio da responsabilidade, segundo Jonas ${ }^{50}$ e Lévinas ${ }^{51}$, não é um conceito ultrapassado esim atual; exige de cada pesquisador inserido no processo biotecnológico que tenha que responder eticamente pelo que faz e, para que isso aconteça, énecessário ter consciência e compreensão das ações desenvolvidas quando está exercendo sua liberdade de escolha. 0 entendimento de princípios éticos e bioéticos são essenciais quando as decisões são tomadas e, ao mesmo tempo, se exercita a liberdade de escolha no labor biotecnológico.

\section{Em relação à política}

A dimensão política da ciência está expressa na declaração anteriormente citada: [...] os países [...] em particular eles deveriam incluir: uma política nacional de longo prazo sobre a ciência a ser de senvolvida junto com os principais agentes do setor público bem como do setor privado; apoio a educação científica e pesquisas científicas [...].

Francis Fukuyama ${ }^{7}$ defende a posição de que o controle político da biotecnologia deveser feito de maneira discriminatória pelo Estado e que os representantes da sociedade el ei tos democraticamentetêm autoridade para estabelecer condições para o desenvolvimento tecnológico. E sobreesse tema ele conclui que a ciência existe para o bemestar humano eo quea comunidade política cos- tuma decidir são parâmetros regulatórios e não os problemas esituações científicas decididas pelo pesquisador em seu laboratório.

No rastro desse tema, o governo brasileiro publicou o Decreto $n-6.041^{52}$, queinstitui a Política de Desenvolvimento da Biotecnologia em nosso país e, no artigo primeiro, parágrafo terceiro, item quatro consta, em relação à bioética: " Bioética: assegurar que as questões e os desafios de natureza ética vinculados à biotecnologia sejam considerados na Política de Desenvolvimento da Biotecnologia;" e a "Biossegurança: garantir a segurança à saúde humana e ao meio ambiente em observância à Convenção sobre Diversidade Biológica e à Lei de Biossegurança".

Percebe-se que, no plano da educação científica, a Política de Desenvolvimento da Biotecnologia ${ }^{52}$ contempla a biossegurança e a bioética e, no plano político regulatório, a Lei de Biossegurança ${ }^{53}$ atende a al guns pontos da declaração.

\section{Consideraçõesfinais}

A biossegurança e a bioética devem estar articuladas para assegurar que a execução das ações em biotecnologia seja respaldada no respeito à vida e ao "outro". A construção da alteridade biotecnológica passa pela educação científica. Uma política de educação científica nacional e não setorial alcançará um maior número de indivíduos e contribuirá mais concretamente para atender a necessidade cada vez mais urgente de formar cidadãos cientificamente esclarecidos e não apenas técnicos, objetivando ter, a médio e longo prazo, pessoas capazes de lidarem com as questões propostas pela biotecnologia. A decisão política de valorizar a biossegurança e a bioética, considerando-as estratégicas na educação científica, se faz necessária no contexto nacional e deve ocorrer de forma efetiva e consistente.

\section{Colaboradores}

M De Bonis participou da concepção, elaboração e revisão; M AF Costa participou da revisão geral, reformulação de trechos do texto e revisão final para publicação. 


\section{Referências}

1. Torres RM. Melhorar a qualidade da educação básica? As estratégias do Banco Mundial. In: De Tommasi L, Warde MJ, Haddad S, organizadores. O Banco M undial e as políticas educacionais. São Paulo: Cortez; 1998.

2. Machado LRS. Educação e os desafios das novas tecnologias. In: Ferreti CJ, organizador. Novas tecnologias, trabalho e educação: um debate multidisciplinar. Petrópolis: Vozes; 1998.

3. Delors J. Educação: um tesouro a descobrir: relatório para a UNESCO da Comissão Internacional sobre Educação para o século XXI. São Paulo: Cortez; Brasília: MEC/Unesco; 1998.

4. Morin $E$. Os sete saberes necessários à educação do futuro. 2a ed. São Paulo: Cortez ; Brasília: Unesco; 2000.

5. Década das Nações Unidas da Educação para o Desenvolvimento Sustentável (2005-2014). Resolução 57/ 254 aprovada pela Assembleia-Geral das Nações U nidas. 2002. [acessado 2008 mai 2 ]. Disponível em: http://www.unesco.pt/pdfs/docs/LivroDEDS.doc

6. Praia J, Gil-Pérez D, Vilches A. O papel da natureza da ciência na educação para a cidadania. Ciênc. \& Educação 2007; 13(2):141-156.

7. Fukuyama F. O nosso futuro pós-humano. Consequências da revolução da biotecnologia. Rio de Janeiro: Rocco, 2003.

8. Nardi R, Gatti SRT. Uma revisão sobre as investigações construtivistas nas últimas décadas: concepções espontâneas, mudança conceitual e ensino de ciências. Ensaio 2004; 6(2):145-168.

9. Costa MAF, Costa M FB. Educação e Competências em Biossegurança. Rev. bras. educ. med. 2004; 28(1):46-50.

10. DeBoer GE. Scientific literacy: another look at its historical and contemporary meanings and its relationship to science education reform. J Res Science Teaching 2000; 37(6):582-601.

11. Fourez G. Alfabetización científica y tecnológica: acerca de las finalidades de la enseñanza de las ciencias. Buenos Aires: Colihue; 1997.

12. Jenkins EW. School science, citizenship and the public understanding of science. Intern J Scien Education 1999; 21(7):703-710.

13. Cachapuz A, Gil-Pérez D, Pessoa AM, Praia J, Vilches $A$. A necessária renovação do ensino das Ciências. São Paulo: Cortez; 2005.

14. Gil-Pérez D, Vilches A, Toscano JC, Macías O. Dé cada de la Educación para un futuro sostenible (2005-2014): un necesario punto de inflexión en la atención a la situación del planeta. Rev Ibero de Educación 2006; 40(2):125-178.

15. Auler D. Alfabetização Científico-Tecnológica para quê? Ensaio 2001; 3(2): 105-115.

16. Krasilchik M. Ensinando Ciências para Assumir Responsabilidades Sociais. Rev de Ensino de Ciên 1985; 14:8-10.

17. Conferência M undial sobre a Ciência para o SécuIo XXI: Um Novo Compromisso. Declaração sobre Ciência e o Uso do Conhecimento Científico. 1999 [acessado 2008 mai. 5]. Disponível em: http:// ftp.mct.gov.br/temas/budapeste/declaracao.htm

18. Costa MAF. Qualidade e Biossegurança: uma necessidade de integração. Rev Biotec 1998; 4:32-33.
19. Dalpian MC. Ensino de ciências e cidadania. Em A berto 1993; 11(55):49-55.

20. American Association for the Advancement of Science. Project 2061: Science for all Americans. Washington, D.C.: AAAS; 1989.

21. Miller JD. Scientific literacy: a conceptual and empirical review. Daedalus 1983; 112(2):29-48.

22. Jenkins EW. Scientific literacy. In: Hunsen T, Postlethwaite TN, editors. The international encyclopaedia of education. Oxford: Pergamon Press; 1994. p. 5345.

23. Maienschein J. Commentary: to the future - arguments for scientific literacy. Science Communication 1999; 21(1):38-63.

24. Shen BSP. Science Literacy. American Scientist 1975; 63:265-268.

25. Leal MC, Souza GG. M ito, ciência e tecnologia no ensino de ciências: o tempo da escola e do museu. In: Atlas do I Encontro $\mathrm{N}$ acional de Pesquisa em Ensino de Ciências; 1997; Águas de Lindóia.

26. Bybee RW. Toward an understanding of scientific literacy. In: Graber W, Bolte C, editors. Scientific literacy. An international symposium. Kiel: IPN; 1997.

27. Shamos MH. Science literacy is futile: try science appreciation. The Scientist 1988; 18(9):17-32.

28. Cazelli S. Alfabetização científica e os museus interativos de ciência [dissertação]. Rio de Janeiro (RJ): Departamento de Educação, PUC; 1992.

29. Hurd PH. Science literacy: its meaning for American schools. Educational Leadership 1958; 16(1):1316.

30. Hurd PD. Scientific literacy: new mind for a changing world. Science \& Education 1998; 82:407-416.

31. Hazen RM, Trefil J. Saber ciência. São Paulo: Cultura Editores Associados; 1995.

32. Schulze CN, Camargo B, Wachelke J. Alfabetização científica e representações sociais de estudantes de ensino médio sobre ciência e tecnologia. Arq Bras Psic 2006; 58(2):1-14.

33. Durant JR. What is scientific literacy? In: Durant JR, Gregory J, editors. Science and culture in Europe. London: Science M useum; 1993. p. 129-137.

34. Laugksch RC. Scientific literacy: a conceptual overview. Science Education 2000; 84(1):71-94.

35. Miller JD. Toward a scientific understanding of the public understanding of science and technology. Public Understanding of Science 1992; 1(1):23-26.

36. Waterman AT. National Science Foundation: a tenyear resumé. Science 1960; 131(3.410):1341- 1354.

37. Jenkins EW. Scientific literacy. In: Husen T, Postlethwaite TN, editors. The international encyclopaedia of education. Oxford: Pergamon Press; 1994. p. 5.345.

38. Freire P. Educação como prática da liberdade. Rio de Janeiro: Paz e Terra; 2007.

39. Freire P. Pedagogia do oprimido. Rio de Janeiro: Paz e Terra; 2007.

40. Krasilchik $M$. Ensino de ciências e formação do cidadão. Em Aberto 1988; 7(40):55-60.

41. Jornal da Ciência (SBPC). [site da Internet] 2008 [acessado 2008 jun 3]. Disponível em: http:// www.jornaldaciencia.org.br/D etalhe.jsp?id=56415 
42. Brasil. Ministério da Saúde. Coordenação de Biotecnologia em Saúde. [site da Internet]. 2008 [acessado 2008 jun 5]. Disponível em: http:// portal.saude.gov.br/portal/sctie/visualizar texto. $\mathrm{cfm} ? \mathrm{idtxt}=22773$

43. Moser A. Biotecnologia e Bioética. Para onde vamos? Petrópolis: Vozes; 2004.

44. Jornal da Ciência (SBPC). [site da Internet] 2008 [acessado 2008 jun 17]. Disponível em: http:// www.jornaldaciencia.org.br/D etal he.jsp?id $=56707$

45. Plano de Desenvolvimento da Educação (PDE) razões, princípios e programas. [site da Internet]. 2008 [acessado 2008 jun 18]. Disponível em: http:/ /portal.mec.gov.br/index.php?option=content\&task $=$ view $\& i d=593 \& \mid$ temid $=910 \&$ sistemas $=1$

46. Brasil. Decreto $n^{0} 6.095$ de 24 de abril de 2007. Estabelece diretrizes para o processo de integração de instituições federais de educação tecnológica, para fins de constituição dos Institutos Federais de Educação, Ciência e Tecnologia - IFET, no âmbito da Rede Federal de Educação Tecnológica. Diário Oficial da União 2007; 25 abr.

47. M inayo M CS. Editorial. Cien Saude Colet 2001; 6(1):2.

48. M inayo M CS. Contribuições da antropologia para dilemas éticos da área da saúde. Cien Saude Colet 2008; 13(2):329-339.

49. Ribeiro OM. Por que investir em pesquisa qualitativa? R. bras. Est. pedag. 2000; 81(197):109-115.

50. Jonas H. El Principio de Responsabilidad: Ensayo de una ética para la civilización tecnológica. Barcelona: Herder; 1995.
51. Lévinas E. De otro modo que ser, o más allá de la esencia. Salamanca: Ediciones Sígueme; 1987.

52. Brasil. Decreto no 6.041, de 08 de fevereiro de 2007. Institui a Política de Desenvolvimento da Biotecnologia, cria o Comitê Nacional de Biotecnologia e dá outras providências. Diário O ficial da U nião 2007; 09 fev.

53. Brasil. Lei no 11.105, de 24 de março de 2005. Regulamenta os incisos II, IV e V do § 10 do art. 225 da Constituição Federal, estabelece normas de segurança e mecanismos de fiscalização de atividades que envolvam organismos geneticamente modificados - OGM e seus derivados, cria o Conselho Nacional de Biossegurança - CNBS, reestrutura a Comissão Técnica Nacional de Biossegurança CTNBio, dispõe sobre a Política Nacional de Biossegurança - PNB, revoga a Lei no 8.974 , de 5 de janeiro de 1995, e a M edida Provisória no 2.191-9, de 23 de agosto de 2001 , e os arts. $5^{\circ}, 6^{\circ}, 7^{\circ}, 8^{\circ}, 9^{\circ}, 10$ e 16 da Lei no 10.814, de 15 de dezembro de 2003, e dá outras providências. Diário Oficial da União 2005; 28 mar.

Artigo apresentado em 15/07/2007

Aprovado em 26/06/2008

Versão final apresentada em 30/10/2008 